\title{
The development of spatial orientation and laterality in physical education classes from the countryside - pilot test
}

\author{
Iconomescu Teodora-Mihaela $^{1 \mathrm{a}}$ and Ciapa Mihaela ${ }^{2}$ \\ 1"Dunarea de Jos" University, Faculty of Physical Education and Sport, Garii Street, No. 63-65, \\ Galati, Romania \\ ${ }^{2}$ National College "Alexandru Ioan Cuza", Saturn Street, No. 26, Galati, Romania
}

\begin{abstract}
The article aims to present a pilot test on the development of space orientation and laterality in pupils in primary education in the physical education lesson. Testing of psychomotricity components was performed by the Piaget Head and Harris test. The differences between the two initial and final tests have shown that through the physical movement of the physical education we have improved the two components of psychomotricity.
\end{abstract}

Keywords: physical education, spatial orientation, laterality

\section{Introduction}

Psychomotricity is a complex function, which integrates and connects the motor elements with the mental ones, determining individual behaviour adjustment and including the participation of different mental processes, thus ensuring the proper execution of response actions to different situations and stimuli.

The study of the motor behaviour during physical education activities and sports is extremely important because, in physical activities, the motor component is prevalent. Motor reactions represent elaborate responses to certain stimuli. It is, therefore, natural for psychomotor abilities to hold an important place in the educational process. This is the reason why the main specific objective of physical education is represented by psychomotor education. [1,4]

In Enciclopedia Universalis - France (1990), we find "The connection between mental and motor and its development within interdisciplinary sciences was named psychomotricity, which may be defined as the result of the integration of motor and mental functions, under the effect of the nervous system maturation, which targets the connection between the subject, his/her body and the environment" [5, p.212]. Horghidan (2000), asserts that "psychomotricity is a primary function, which comprises mental phenomena in

${ }^{a}$ Corresponding author: Teodora.Iconomescu@ugal.ro 
its structure, generated by body movements and expressed by means of voluntary movements, whose use is conditioned within actions" [8, p.32].

At the beginning, studies approached psychomotricity from the point of view of motor development and of its relationship with intelligence. Nowadays, studies take into account both the motor structures and their connection with the body scheme, ideomotricity, laterality, with the spatial and temporal structure and the ways of learning and adaptation of the individual within society. The study of psychomotricity occupies an important place in the organization of the educational process. This doesn't only engage the motor activity, but it also involves the presence of the intellectual and perceptive functions. Each individual's psychomotor habits evolve depending on the abilities he/she possesses, on the degree of physical and intellectual development and on the educational environments in which he/she was educated during childhood. [2, 3, 7]

For these reasons, we believe that the education of psychomotricity from an early age must be one of the constant concerns for parents and teachers alike and it must also be focused on during the other stages of human existence, too.

It is well-known that certain behaviours of the human subject depend, in point of structure and of their manifestation, on nature and on the characteristics of the stimuli that cause them, but they also depend on the idiosyncrasies that characterize each and every person. It is therefore important that the entire effect of the educational process also depend on the subject's personality dynamics, within which psychomotor abilities play an extremely important part.

\section{Methods}

The research was realised through a pilot test over during the school year 2015-2016, we tested and assessed a number of 32 fourth grade students, with ages ranging from 10 to 11 years, from Primary School, Bucești, county of Galați.

As psychomotor assessment methods, we used the Piaget Head spatial orientation test and the Harris laterality test [6].

The initial test was conducted at the beginning of the school year. After this test and after test analysis, we proposed that, during school year, one of the two classes of physical education should be dedicated to the development of psychomotricity by means of movement games.

After final testing, the results were statistically analysed by the absolute and relative frequency achieved through the program SPSS 23.

\section{Results and discussions}

In order to determine the subjects' spatial orientation index education level we used the spatial orientation test - Piaget Head, and the statistical results are presented in table 1 and table 2 .

Table 1. The statistical results at the initial test in the space orientation test

\begin{tabular}{|l|c|c|c|c|}
\hline Items & Frequency & Percent & Valid Percent & $\begin{array}{c}\text { Cumulative } \\
\text { Percent }\end{array}$ \\
\hline Test successful & 16 & 50.0 & 50.0 & 50.0 \\
\hline Test corrected spontaneously & 3 & 9.4 & 9.4 & 59.4 \\
\hline Test unsuccessful & 13 & 40.6 & 40.6 & 100.0 \\
\hline Total & 32 & 100.0 & 100.0 & \\
\hline
\end{tabular}


Table 2. The statistical results at the final test in the space orientation test

\begin{tabular}{|l|c|c|c|c|}
\hline Items & Frequency & Percent & Valid Percent & $\begin{array}{c}\text { Cumulative } \\
\text { Percent }\end{array}$ \\
\hline Test successful & 18 & 56.3 & 56.3 & 56.3 \\
\hline Test corrected spontaneously & 5 & 15.6 & 15.6 & 71.9 \\
\hline Test unsuccessful & 9 & 28.1 & 28.1 & 100.0 \\
\hline Total & 32 & 100.0 & 100.0 & \\
\hline
\end{tabular}

In the Piaget Head test, conducted on 10-year old children (fig. 1), we noticed an improvement in task-solving of $22.7 \%$, raising from $70.8 \%$, within the initial test, to $93.5 \%$ within the final test.

\section{Piage Head Test, 10 years}

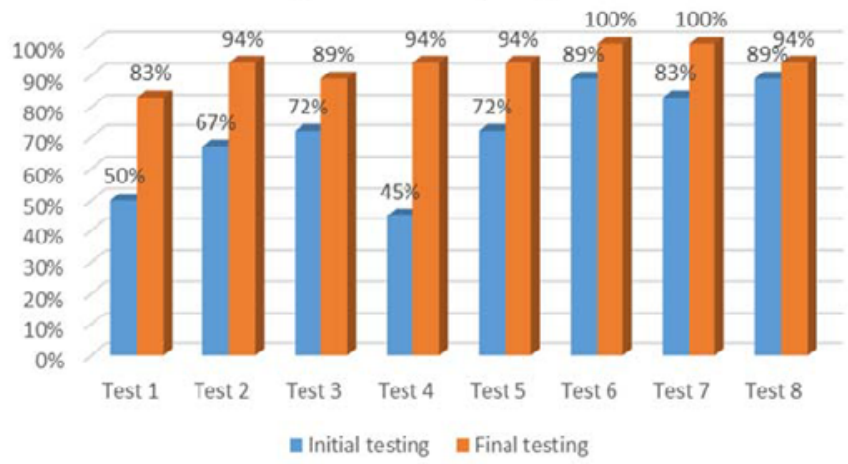

Fig. 1. Comparative results of the Piaget Head test at students in 10-year-olds

Together with an increase in age, due to a greater understanding ability, the difference in point of percentage between the two tests, the initial one and the final one, raises, reaching approximately $30 \%$, the evolution of the students being from $63.2 \%$ within the initial test to 93\% within the final test.

For the Harris laterality test, the statistical results were the ones presented in table 2 and, afterwards, graphically presented in the figures 1 and 2 .

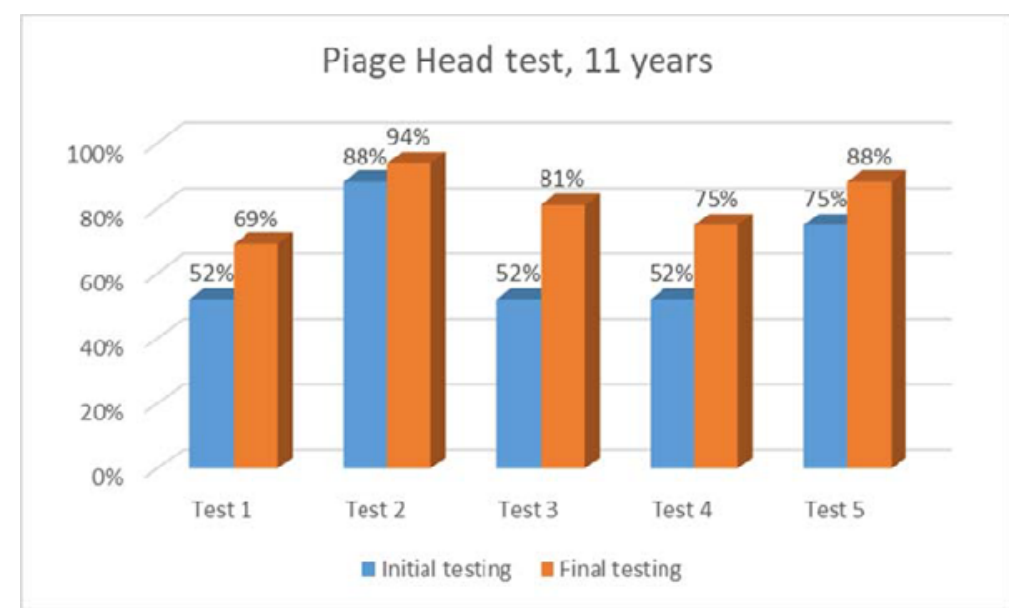

Fig. 2. Comparative results of the Piaget Head test at students in 11-year-olds 
In the first step of the test (the initial test), right-handed people and cross laterality (figure 3), the 10-year old students presented numerical values, which were nearly equal $(46 \%, 47 \%)$. After the final test, we notice the tendency to favour the development of the most used side (the right-handed students), this change becoming obvious for the students with cross laterality, the migration percentage being of $14 \%$.

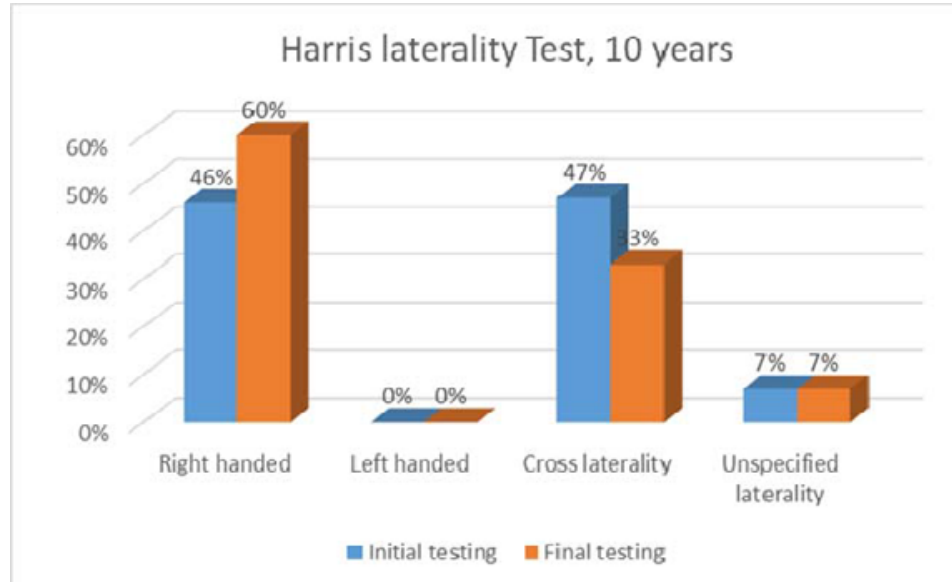

Fig. 3. Comparative results of the Harris laterality test at students in 10-year-olds

From the Harris laterality test graph, describing the 11-year old students (figure 4), we may draw the conclusion that the children's motor capacity improvement is obvious, starting from $12 \%$, heading towards being ambidextrous and reaching $41 \%$. This fact is due to the implementation of the movement game-based program in order to educate the psychomotor components.

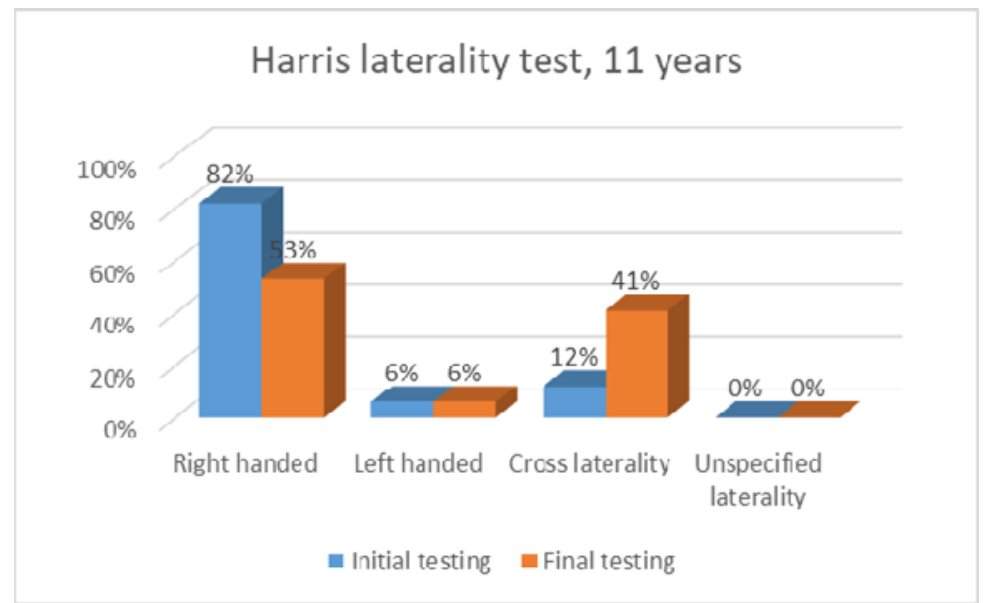

Fig. 4. Comparative results of the Harris laterality test at students in 11-year-olds

According to the results of the Piaget Head test, we discovered the fact that the participation in the program created for pre-school children's psychomotor ability education for the age of 10, succeeded in raising the spatial orientation indexes with an average of $22.7 \%$, recording a value with $30 \%$ greater for 11 -year old children. From here, we may deduce that the degree of involvement and awareness also increases depending on the age of the subjects involved in the research. 
In the final test, by using the Harris laterality test, we find out the importance of the classmate environment influence, since the majority of the 10-year-old subjects (who are, obviously, more impressionable than 11-year-olds as far as the social and educational requirements are concerned), adapt and tend to use the right side as the dominant side, the laterality index moving from Cross laterality to right-handed in a percentage of $14 \%$, whereas the 11-year-olds, are predominantly right-handed, the laterality index becoming, thus, stable.

\section{Conclusion}

Starting from the determination of the initial and final psychomotor levels, which resulted from the interaction of the morpho-functional factors (internal factors) and of the social and educational ones (external factors) with the motor education, we may draw the following conclusions:

- from a psychomotor point of view, the students follow the alternating stages of the biological factors' evolution and this is the reason why the results are different;

- in order to have a good relationship between efficiency and quality, the psychomotor education level and objective setting must be performed by taking into consideration the individual age and sex particularities as well as modern society requests;

- the stimulation of different age-specific processes, by means of an educational program based on the movement game method, such as: a harmonious physical development, the playful behaviour, the need for affirmation and competition successfully contribute to the education and formation of primary school student psychomotricity; the subjects' morpho-functional particularities require the use of certain tests, of specific methods and means, acknowledging the individual routes that are followed by psychomotor education and genetic evolution;

- by analysing the first results (the initial tests), we notice a negative influence from the part of modern civilization (the standard of living, technology, automation, sedentariness, the replacement of outdoor games with video games) on the motor age of pre-school children. This is the reason why we recommend an interventional strategy in the educational process, by means of movement-based games, in order to favour the development of primary school students' psychomotor abilities.

The main conclusion is that the use of game-based training program in the teaching activity leads to the acquisition of obvious and more valuable psychomotor abilities as compared to the simple use of methods based on simple strength training, sprint, longdistance (endurance) running, coordination capacity exercises, thus confirming the researched hypothesis.

\section{References}

1. A.C. Macri, The role of the exercises in the improvement of the psychomotricity components in the development of the pupils, Sport \& Society / Sport si Societate, Special Issue, 14, 155-162, (2014)

2. A.C. Cappellini, S. Mancini, S. Zuffellato, F. Bini, P. Polcaro, A.A. Conti, R. Molino Lova, C. Macchi, Environmental effects on school age child psychomotricity, Minerva Pediatrica, 60(3):277-84, (2008).

3. C. Strujan, D. Bădău, A. Bădău - Physical education. Teacher guide, Publishing House Ria of Botosani, (2009).

4. D. Bădău, F. Dusa, A. Bădău, Physical education and sport.., Publishing University Press, Tirgu Mures, (2015). 
5. Encyclopaedia Universalis, Edité par Encyclopaedia universalis France, (1990).

6. I. Lozincă, V. Marcu, Psihologia şi activităţile motrice, Oradea University Press pp. 125-136, (2005).

7. S. Pratesi, M. Fasano, A.C. Cappellini, Effects of a psychomotor education program on Body Mass index (BMI) in a group of school- aged Italian children, Journal of Anatomy and Embryology, 117(2), 152, (2012).

8. V. Horghidan, Problematica psihomotricităţii, Editura Globus, Bucureşti. (2000). 